Inkyu Jeong et al., Int. J. of Safety and Security Eng., Vol. 6, No. 1 (2016) 19-29

\title{
IMPROVEMENT OF THE BUSINESS MODEL OF THE DISASTER MANAGEMENT SYSTEM BASED ON THE SERVICE DESIGN METHODOLOGY
}

\author{
INKYU JEONG $^{1}$, JIWON SEO ${ }^{1}$, JUNGTAK LIM ${ }^{1}$, JAEHO JANG ${ }^{2} \&$ JINYOUNG KIM ${ }^{1}$ \\ ${ }^{1}$ Disaster Management Research Division, National Disaster Management Institute, South Korea. \\ ${ }^{2}$ Convergence Department, JBT Corporation, South Korea.
}

\begin{abstract}
The type and scale of disasters are changing with the changing social structures in modern society. Natural, social and human disasters occurred individually in the past, but the complexity and scale of these disasters have increased recently. As a result, National Disaster Management Institute (NDMI) has been operating the Smart Big Board (SBB) system to ensure effective real-time disaster management since June 2013. Based on Web GIS, this system can rapidly manage various types of information pertaining to disasters. However, it has not been able to satisfy all users because it was not developed keeping in mind the needs of service users. This study attempts to improve the SBB service using the service design methodology that is currently being widely used to improve public services. The service design process is conducted in accordance with the double diamond model, which utilizes a customer journey map to locate the contact point between user and service. This improved system is especially able to perform user customized disaster management in response to various and complex disaster types. If the improved system is applied to the national emergency management system through the business model design process, it will be able to effectively manage any future disasters.
\end{abstract}

Keywords: disaster management system, service design, smart big board.

\section{INTRODUCTION}

Modern society has graduated from being an industrial economy that merely mass-produced goods and services to being a service-oriented one. In recent years, service quality has increasingly been considered as vital in ensuring customer satisfaction. Edvardsson and Olsson [1] explain that although services play a predominant role with respect to GDP and employment in Organisation for Economic Co-operation and Development (OECD) countries, we know very little about the quality management of service operations. Therefore, the service design process that has been constructed from the standpoint of the service provider must now be designed keeping the service consumer (customer) in mind.

Alam [2] proposed that service marketing (design) is different from tangible product marketing because services are characterized by intangibility, heterogeneity, perishability and inseparability. In particular, an important characteristic of an economy making a transition to a service-oriented one is its gradual shift to a user-centric and an intangible assets-centric approach. Therefore, Kaner and Karni [3] explain that the development process of a new service may be different from the development process of a new tangible product, and thus, more research in the area of new services is desirable. Whyte et al. [4] found that many service industries are facing a rapidly changing market, increasing deregulation, emerging 
technologies such as the Internet and e-commerce, skills shortage and more demanding customers. Kimbell and Seidel [5] explained that many service firms are recognizing the need to develop new service offerings that are timely and responsive to user needs in order to remain competitive in these turbulent and rapidly changing markets.

Winch [6] explains that the power of economic activity has moved from the provider to the consumer. Therefore, to analyze the needs of the consumer, science and technology are being increasingly used. In response to this tendency, many companies have increased their research in understanding and analyzing their consumers. As a result, of late "service design" has been attracting much attention.

Papazoglou and Yang [7] and Papazoglou and van den Heuvel [8] explain that, in particular, web-based public services are providing useful information on people's lives and national policy through their relevant department websites. However, existing web-based public services are not comprehensive enough because they are not designed to take into account the user, which merely shows their inability to do so to service providers. Therefore, web-based public services need to be designed with the consumer demand in mind. For this purpose, specific solutions to the service providing methods are required.

Korea's National Disaster Management Institute (NDMI) has been operating the Smart Big Board (SBB) system for effective real-time disaster management since June 2013. This system is based on Web GIS, which can rapidly manage various types of information pertaining to disasters. However, it has not been able to satisfy all users, because it was not developed keeping in mind the perspective of the service users. We have therefore conducted a study to improve the SBB service using the service design methodology.

\section{SERVICE DESIGN METHODOLOGY}

\subsection{Basic concepts}

The service design methodology is a standardized method that uses various design process elements to implement service design work. For modern design work, the Double Diamond model-based design methodology is used universally (Fig. 1). Devised by the UK's Design Council, the Double Diamond design method consists of four steps: Discover, Define, Develop and Deliver. In the first diamond area, the challenges of service and development opportunities are discovered; in the second diamond area, the concepts of services that need changing are devised and ideas that need materializing are organized. Typically, the design process is believed to occur in the second diamond area, and to specify the design that develops intangible services, it is very important to determine whether it is possible to clearly discover and define the touch point during the first diamond steps.

Of late, the service sector has diversified and many services require considerable prior knowledge. Thus, various forms of modified methodologies are being applied depending on the service characteristics. During the service design stage, numerous process elements are used, as indicated in Table 1. The detailed elements used during each stage play a significant role in increasing the completeness of the service design results.

\subsection{Discover}

Forty institutions that are conducting trials of the SBB system at the NDMI as of July 1, 2014, were used as subjects to conduct field research and in-depth interviews. By doing so, customer 


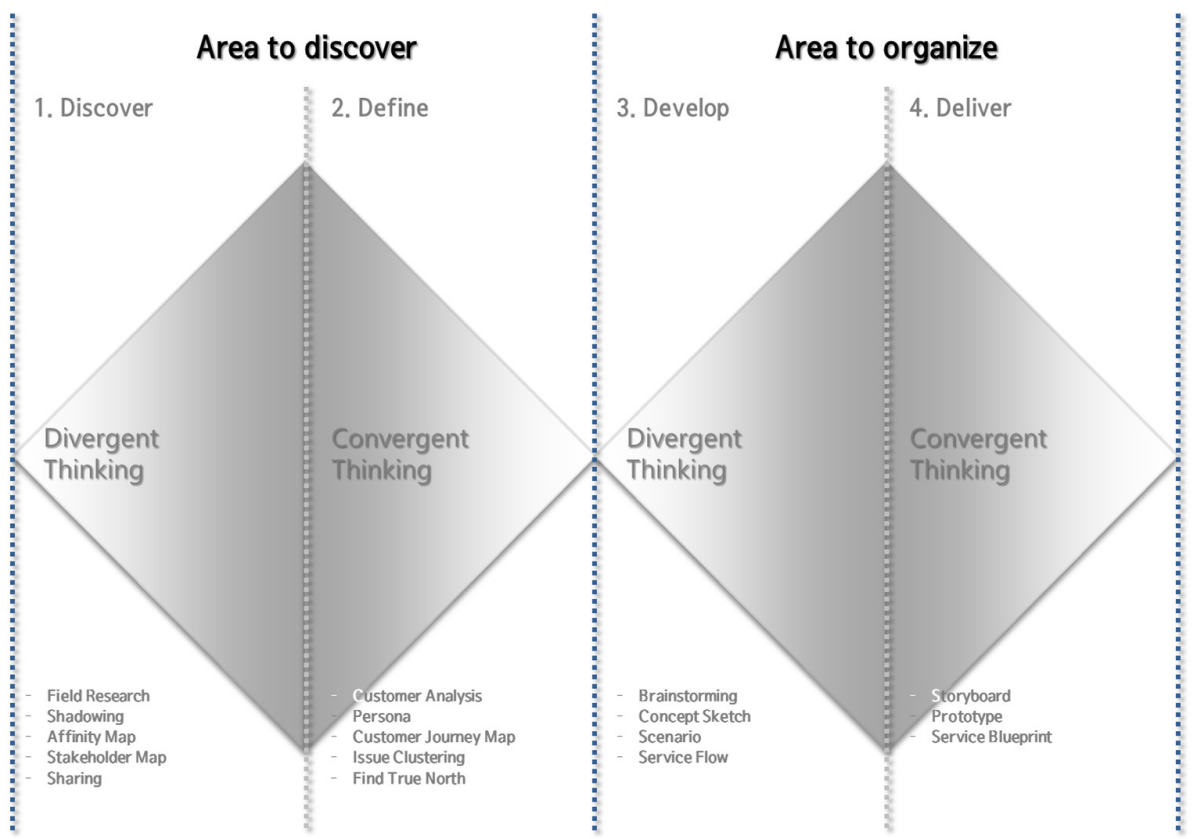

Figure 1: Double diamond model designed by UK's design council.

demands were deducted, and groups of final service customers were defined. Further, the objectives of service design as per the system were established.

Field research and in-depth interviews were conducted five times from May to June 2014. The subjects were primarily divided into groups of general users (citizens) and professional users (disaster management personnel). The professional user group consisted of the local government's disaster management personnel and disaster management-related agencies. Focus group discussions were conducted for each group. The general user group consisted of unspecified citizen participants of exhibitions related to disaster and IT techniques. Surveys were conducted after this group directly experienced and conducted trials.

\subsection{Define}

In the Define phase, significant meanings of investigated materials were determined to determine key issues, which were used to decide the direction of the service strategy that provides value to the customer. Customer analysis is a method used to select the standards for users actually using the service, which determines their demands and the values that service providers should offer. The objective of this process is to grasp the characteristics of the customer group. The results of customer analysis are represented in Fig. 2. Customer category analysis showed that the SBB systems expected user group consists of all citizens that take up the most part. However, when user behaviors are observed, the functions mainly used are those pertaining to disaster management personnel of public institutions. Thus, the current SBB system's main user group is limited to disaster management personnel.

The persona sheet helps understand the physical and psychological characteristics of the analyzed user group along with their experience and knowledge. It creates a model of a 
Table 1: Design elements in the service design process.

\begin{tabular}{|c|c|c|}
\hline $\begin{array}{l}\text { Design } \\
\text { steps }\end{array}$ & & Design process elements \\
\hline \multirow[t]{6}{*}{ Discover } & Field research & $\begin{array}{l}\text { For understanding customer needs through field } \\
\text { experience }\end{array}$ \\
\hline & Shadowing & $\begin{array}{l}\text { Observing the entire service process from the cus- } \\
\text { tomer's viewpoint }\end{array}$ \\
\hline & In-depth interviews & $\begin{array}{l}\text { Process of comprehending the user's implicit require- } \\
\text { ments and deriving the key issues }\end{array}$ \\
\hline & Affinity map & $\begin{array}{l}\text { Process of deriving patterns by classifying the col- } \\
\text { lected information }\end{array}$ \\
\hline & Stakeholder map & $\begin{array}{l}\text { Process of visualizing the relationship between the } \\
\text { stakeholders associated with the service }\end{array}$ \\
\hline & Sharing & $\begin{array}{l}\text { Process of sharing the clues found during the design } \\
\text { process with team members }\end{array}$ \\
\hline \multirow[t]{5}{*}{ Define } & Customer analysis & $\begin{array}{l}\text { To understand the customer's characteristics, is } \\
\text { provided with criteria to determine the want to what } \\
\text { services. }\end{array}$ \\
\hline & Persona & $\begin{array}{l}\text { Virtual model setting to provide the criteria for the } \\
\text { elements of service improvement }\end{array}$ \\
\hline & Customer journey map & $\begin{array}{l}\text { To visualize customer service touch points based on } \\
\text { time flow }\end{array}$ \\
\hline & Issue clustering & $\begin{array}{l}\text { Process of finding a significant issue among the } \\
\text { investigated information }\end{array}$ \\
\hline & Find true north & $\begin{array}{l}\text { To establish a direction of service improvement } \\
\text { based on the major issues that have arisen }\end{array}$ \\
\hline \multirow[t]{4}{*}{ Develop } & Brainstorming & $\begin{array}{l}\text { Process of expanding an idea in several directions } \\
\text { without any restrictions }\end{array}$ \\
\hline & Concept sketch & $\begin{array}{l}\text { To visualize important concepts for communication } \\
\text { with stakeholders }\end{array}$ \\
\hline & Scenario & $\begin{array}{l}\text { The interactive hypothesis is used to describe the } \\
\text { service concept }\end{array}$ \\
\hline & Service flow & $\begin{array}{l}\text { To create a flow chart for implementing the actual } \\
\text { service }\end{array}$ \\
\hline \multirow[t]{3}{*}{ Deliver } & Storyboard & $\begin{array}{l}\text { Process of using cartoons to make it easier to sell a } \\
\text { service concept to a customer }\end{array}$ \\
\hline & Prototype & $\begin{array}{l}\text { Provides users the experience of actually using a } \\
\text { service that is not yet complete }\end{array}$ \\
\hline & Service blueprint & To visualize the service delivery process in detail \\
\hline
\end{tabular}




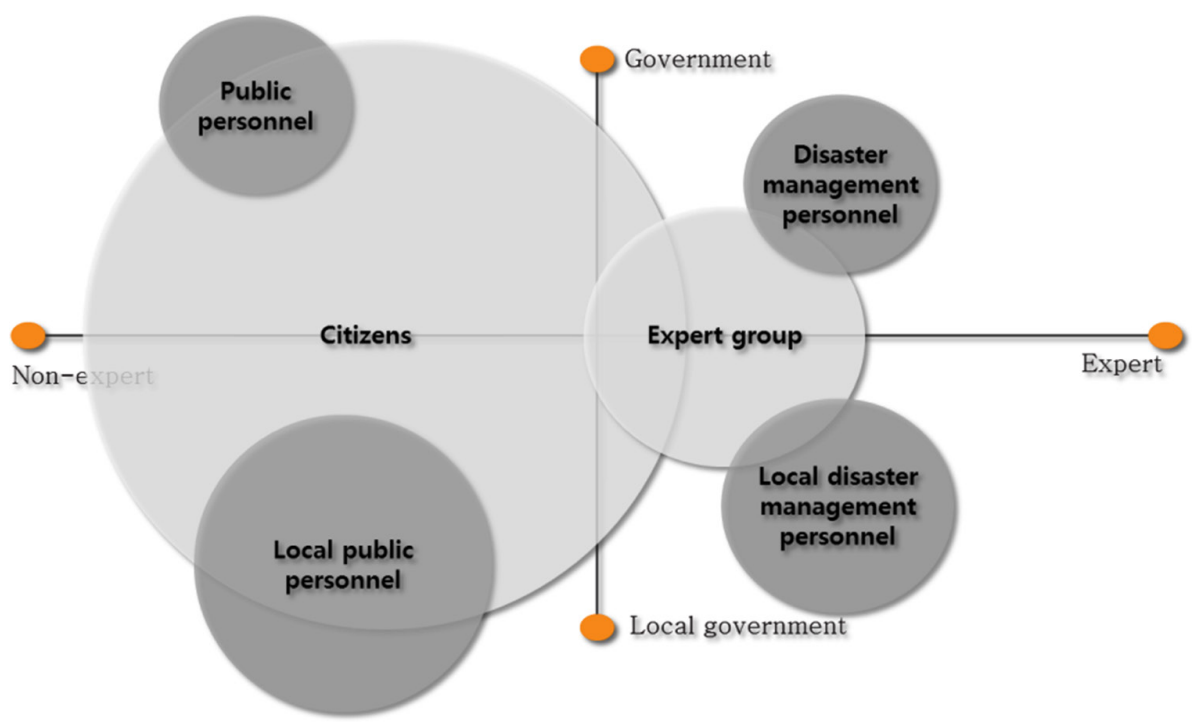

Figure 2: Results of customer analysis.

virtual customer by using knowledge about the customer; this process identifies the characteristics of new services to be developed and the required elements. Persona identifies customers groups with similar behavioral patterns, persuades stakeholders during service concept creation and aids in decision-making. Typically, the persona of civil services tends to use famous celebrities or public figures to enhance customers' sympathy and service intimacy. However, since disaster management personnel were selected as the main user group of the SBB system, it would be more effective to select the related public official group as the persona.

The customer journey map is a method used to visualize the user's experience based on time flow. It is helpful when intangible services are analyzed in detail. When visualizing the customer journey map, it is important to ensure the feelings of the service interaction and user are easy to understand. By doing so, the existing service environment from the user's point of view can be improved and understood. Ideas to develop a realistic service concept and optimal experience can be drawn.

The SBB system classifies the customer journey map flow created by the disaster management system service into "ordinary" and "emergency." In the event of the July 27, 2011, floods in Seoul, disaster management personnel were interviewed and similarities in their various demands were summarized to derive service objectives.

\subsection{Develop}

In the Define phase, the service objective derived is used to observe a number of design methodologies and develop a final service concept. In this step, the brainstorming process of the team members implementing the services design is important to discard constraints regarding accidents and draw ideas beyond the technical limitations. 


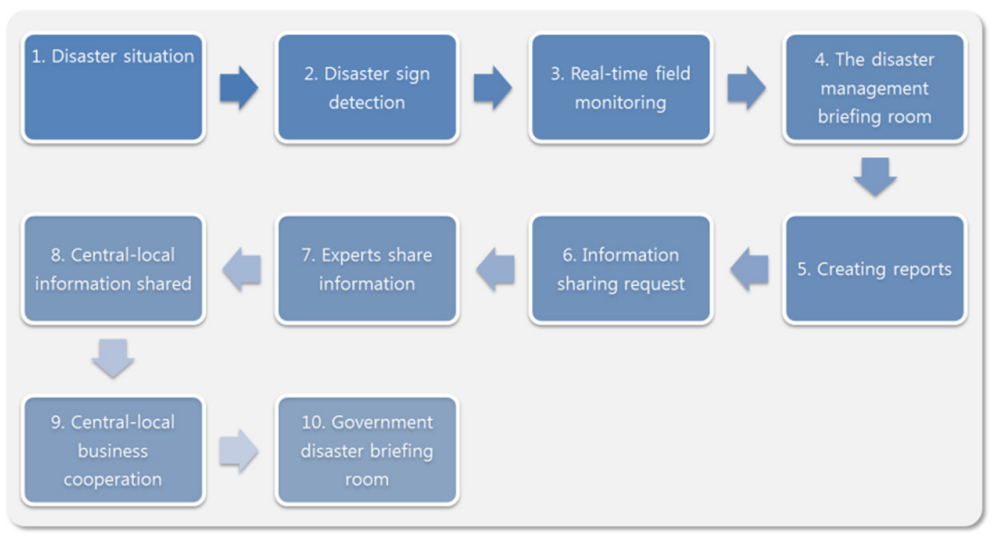

Figure 3: Complete service scenario created through brainstorming.

The ideas derived through brainstorming are visualized during the concept sketching process. This results in the sharing and rapid development of ideas and allows for smooth communication between the designer and developer. After the concept sketching process, detailed information is added and a service scenario in the form of a story is created.

By creating a service scenario, potential challenges that the newly changed service may face are observed beforehand, and a more detailed inspection of the service can be conducted. Moreover, the service scenario eventually helps in understanding the important elements that decide the service experience and reviews them in advance. It also helps share all knowledge pertaining to the service.

To develop the SBB service, the concept sketch was replaced by the following process. First, the ideas derived from the brainstorming between the design groups members were organized, followed by the functions required by each customer demand level. Figure 3 represents the completed service scenario created through brainstorming.

\subsection{Deliver}

To deliver this scenario, the end product of the service design is introduced to customers, who, in turn, are persuaded to apply and improve the product. It is the last step in implementing the entire process of service design. In this step, a comprehensive service blueprint for mapping out the service touch point and hidden process between the customer and service provider is created. This blueprint shares the overall context among the stakeholders who influence the delivery process of the developed service. By understanding each of their roles, the new service is implemented in a stable manner.

The service blueprint can be used throughout the design process. During the initial steps, it can be used to observe the various aspects of the service being currently provided. During the design process, the contents can be enriched to increase the quality of the design results as the service concept is gradually developed. Since the SBB system limits the users to disaster management personnel, in the event of a disaster situation, the response process is selected as the first user behavior. The service blueprint was created based on the point of contact and the improvements to the customer journey map and service scenario creation process. Figure 4 represents the completed service blueprint created through the service design process. 


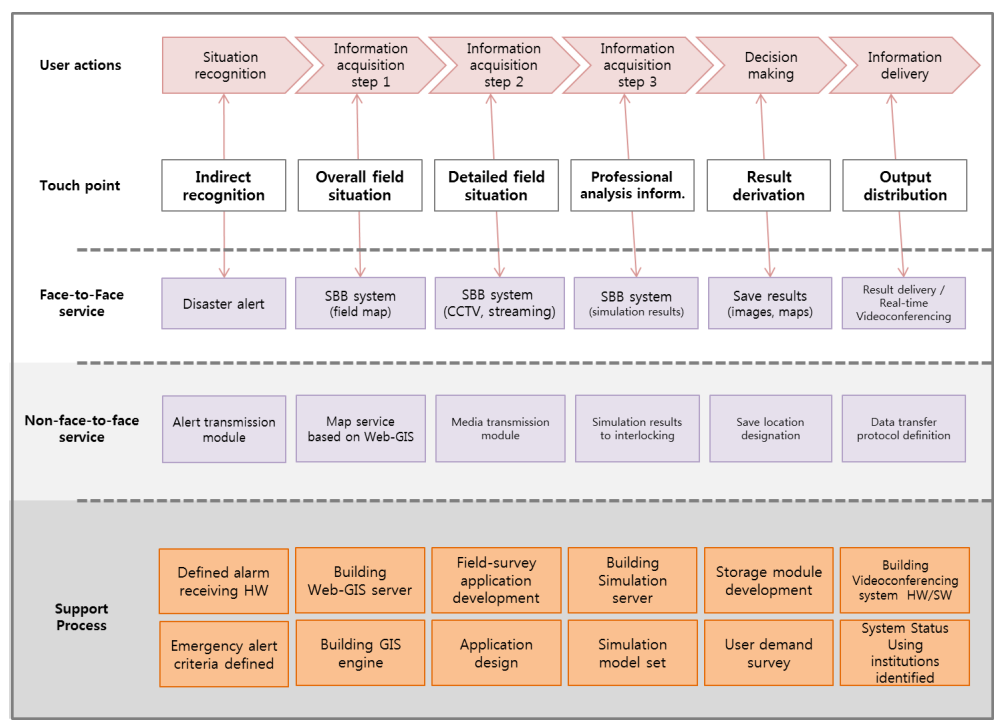

Figure 4: Service delivery process of the SBB system.

\section{IMPROVEMENT RESULTS}

\subsection{Improved overall user interface}

Results of the field research and in-depth interviews indicated that the complicated user interface (UI) system required the most improvements. In the existing system shown in Fig. 5, the map window where the information is displayed varies depending on the resolution of the web browser. The size of the menu located on the left- and right-hand side of the window is fixed in size. Thus, at the system's minimum resolution $(1,280 \times 1,024)$, the menu essentially takes up over $30 \%$ of the space. This space decreases as the browser size increases; however, owing to the fixed menu allocation, results showed that the concentration of the information displayed decreases.

Moreover, with respect to the information list registered in the system, the menu service is simply written in text, but the font size is very small, thereby reducing its legibility. Thus, first-time users of the system need a lot of time to locate the required information.

In order to address these points, the text displayed on the main screen was minimized and icons were created in order to achieve maximum concentration on the map area. This way, the map window's resolution could be changed to take up $90 \%$ of the entire browser, thereby increasing the information display. The size of the icons was reduced to one-third of those in the previous system.

Moreover, menus that were turned into icons could be expanded or reduced, enabling users to focus on the map when necessary. Figure 6 represents the UI design of the SBB system improved through the service design process.

\subsection{Function of help desk}

For first-time users of the disaster management system that requires professional knowledge, there is a high entry barrier for smooth system use. Taking this into consideration, a Help 


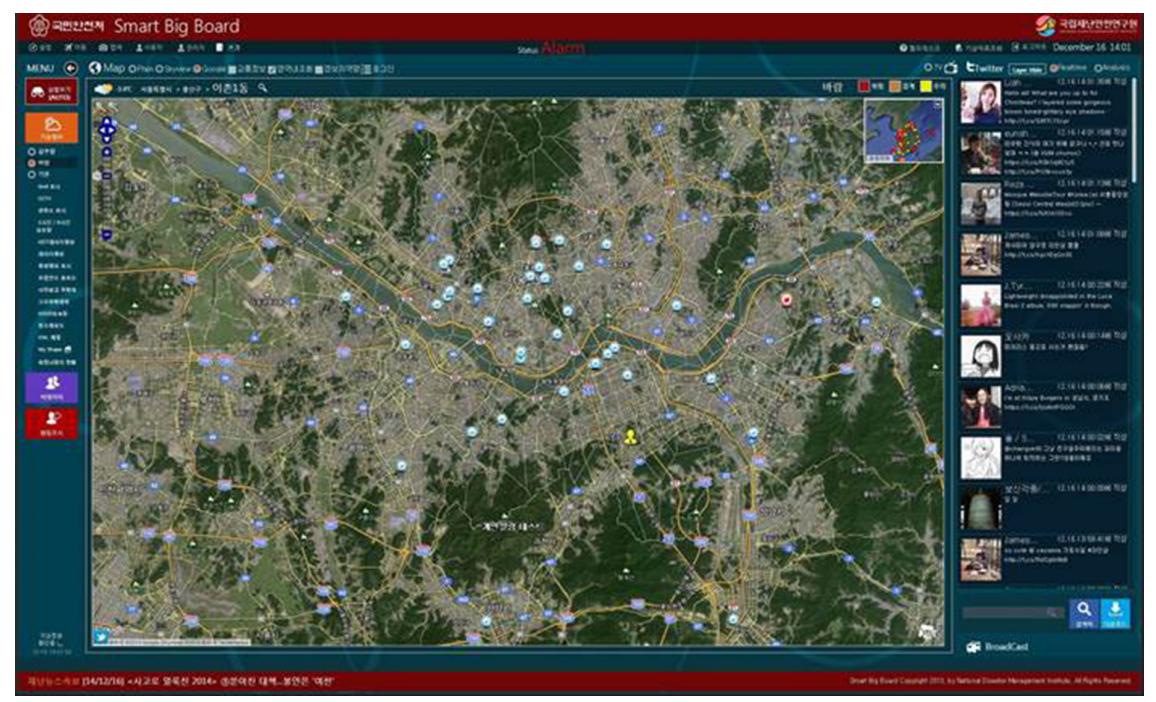

Figure 5: The existing systems developed in 2013.

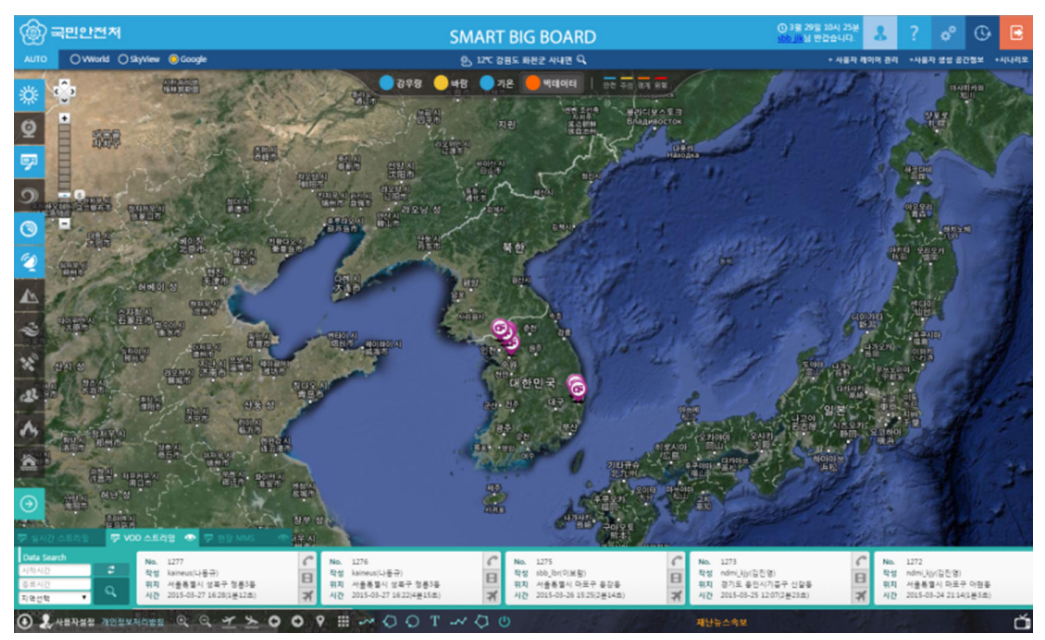

Figure 6: The improved UI design of the SBB system.

Desk menu that gathers users' inquires was set up. The help desk will be used to distribute manuals and receive continuous feedback about the system. Moreover, based on future municipalities for a test-bed of users' experiences, additional improvements will be made and carried out in phases. Figure 7 represents the new help-desk functions on the SBB system, which was improved through the service design process.

\subsection{Custom function configuration}

The SBB system can integrate varied disaster management information and display and manage it. However, actual user interviews indicated that information used for disaster types and regions is different. Displaying too much of the system can actually reduce its effectiveness. 


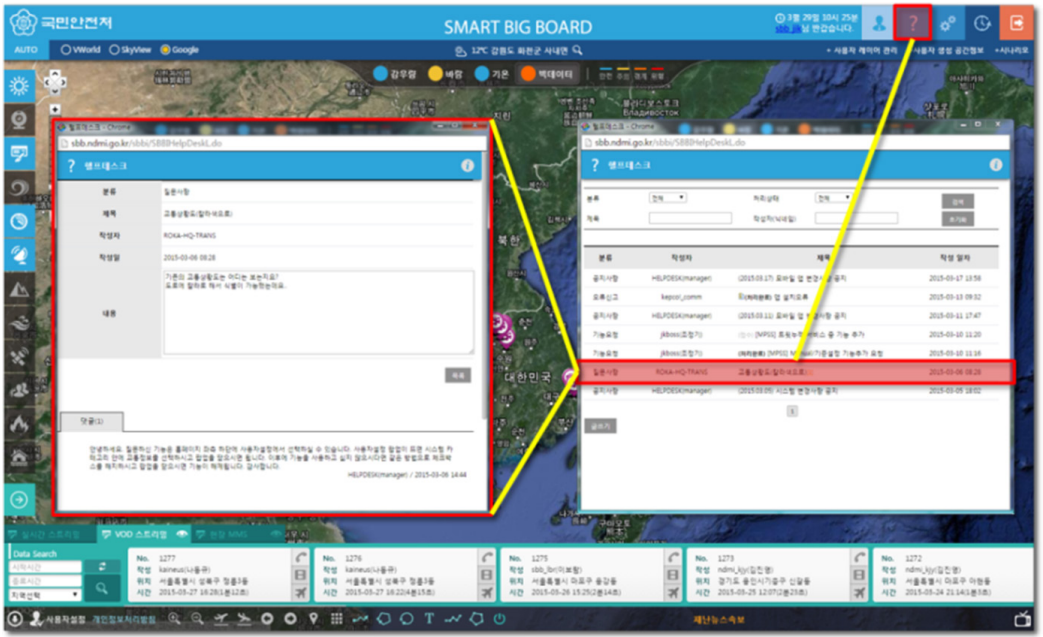

Figure 7: The new help-desk functions on the SBB system.

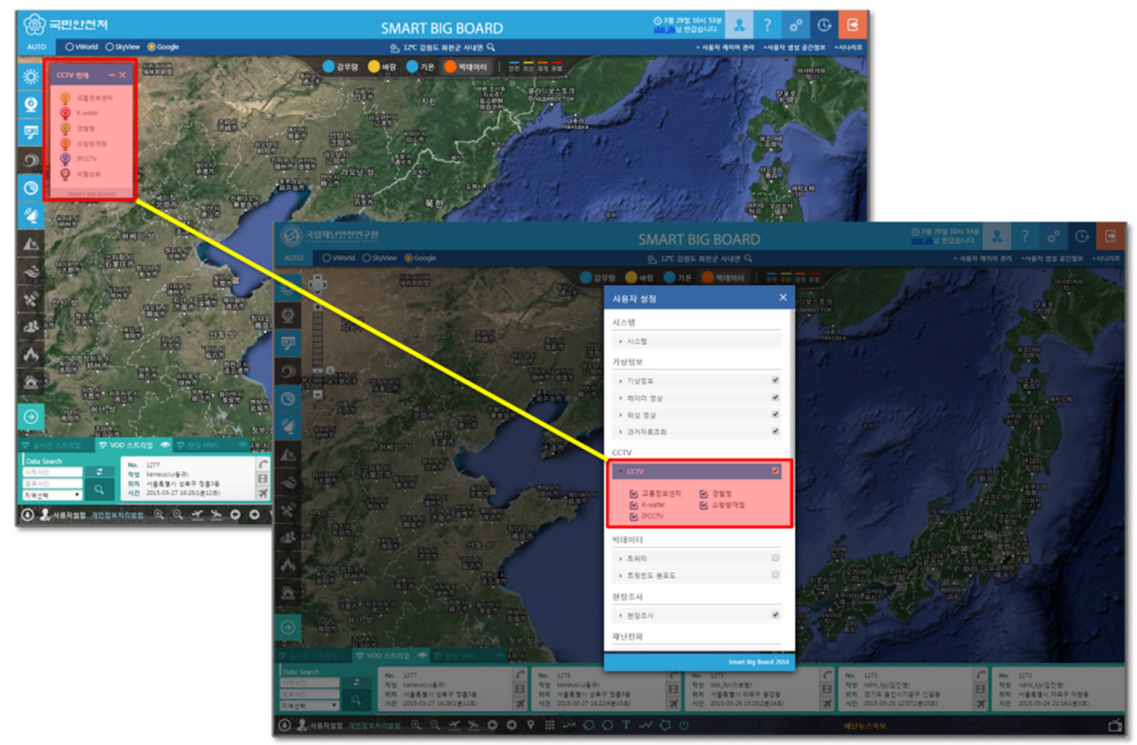

Figure 8: Menu control screen seen through user settings.

In the existing system, the information that needs to be displayed can be selected and displayed; however, all the disaster management information in the system is displayed on the menu (in text format), which has given rise to many issues. In addition, this type of menu format may appear to have a lot of content, but since only a portion of the information is actually needed by each user, the issue of decreased applicability arises.

In the improved system, through the initial "user settings" menu, only the needed information is selected and displayed on a menu, as shown in Fig. 8. In the second step, the system was improved such that only the information on the menu can be selectively displayed. In the future, a method to control the information to suit user needs will be introduced. 


\section{CONCLUSION}

As the quantitative demand for information is being satisfied, the greatest dilemma in the current disaster management sector is finding and easily using relevant information amid a great deal of information in a timely manner. To resolve this issue, the NDMI has focused on two environmental changes: it has propelled the government 3.0 to open up, share information and break down the walls between departments. Moreover, it has carried out technological developments with respect to information and communications technology (ICT) and mobiles. Along with this national policy stance and ICT, the SBB was developed to be consistent with the social demand for safety in disaster situations, which has caused many reverberations.

However, the SBB system is relatively new and still involves several issues to be resolved. If efforts need to be made to map out the basis of the open platform, secure the information link base or expand users, the process of completing the link plant form between information systems, interlocking information gathering equipment, developing a risk assessment support for big data and customized management service development is important in stringing them together.

Among the SBB service design improvements discussed and important issues to be solved in the future is the enhancement of a web-based public service. While Internet Explorer (IE) covers $90 \%$ of the web browser market in Korea, there continue to be many difficulties with respect to service environment developments through the web. However, since 2004, the Web Hypertext Application Technology Working Group (WHATWG) has started detailed work on creating HTML 5 the next core standard, and global IT firms are competing to take the lead in this area.

Web-based services that can freely materialize various graphic effects and videos on the Internet browser without having to install additional programs are useful techniques in information sharing and services. That SBB developed based on the Chrome browser can be viewed as an effort to follow the international HTML 5 standard.

In the future, there are plans for research on technology development, link and development standardization and platform operation technology. Test bed operations and inter-organizational operations between local governments and public institutions will be carried out in the long run for the expansion of link materials and user institutions and the inspection of development functions. This will serve as a foundation for the development of a SBB that is more stable and optimized for users.

\section{REFERENCES}

[1] Edvardsson, B. \& Olsson, J., Key concepts for new service development. The Service Industries Journal, 16(2), pp. 140-164, 1996. http://dx.doi.org/10.1080/02642069600000019

[2] Alam, I., An exploratory investigation of user involvement in new service development. Academy of Marketing Science, 30(3), pp. 250-261, 2002. http://dx.doi.org/10.1177/0092070302303006

[3] Kaner, M. \& Karni, R., Design of service systems using a knowledge-based approach. Knowledge and Process Management, 14(4), pp. 260-274, 2007. http://dx.doi.org/10.1002/kpm.292

[4] Whyte, J., Ewenstein, B., Hales, M. \& Tidd, J., Visualizing knowledge in project-based work. Long Range Planning, 41(1), pp. 74-92, 2008. http://dx.doi.org/10.1016/j.lrp.2007.10.006 
[5] Kimbell, L. \& Seidel, V.P., Designing for services - multidisciplinary perspectives. Proceedings of the Exploratory Project on Designing for Services in Science and Technology-based Enterprises, Oxford: Fine print, 2008.

[6] Winch, G.M., Internationalization strategies in business-to-business services: The case of architectural practice. The Service Industries Journal, 28(1), pp. 1-13, 2008. http://dx.doi.org/10.1080/02642060701725347

[7] Papazoglou, M. \& Yang, J., Design methodology for web services and business processes. Proceedings of the Third International Workshop on Technologies for E-Services, pp. 54-64, 2002. http://dx.doi.org/10.1007/3-540-46121-3_8

[8] Papazoglou, M. \& van den Heuvel, W.J.A.M., Service-oriented design and development methodology. International Journal of Web Engineering and Technology, 2(4), pp. 412-442, 2006.

http://dx.doi.org/10.1504/IJWET.2006.010423 